\title{
Incorporating Physics Principles in General Biology to Promote Integrative Learning and Thinking
}

\author{
Tennille D. Presley, Winston-Salem State University, USA \\ Noelle A. Harp, Winston-Salem State University, USA \\ Latrise S. Holt, Winston-Salem State University, USA \\ Destini Samuel, Winston-Salem State University, USA \\ Jill JoAnn Harp, Winston-Salem State University, USA \\ iD https://orcid.org/0000-0003-0845-0682
}

\begin{abstract}
Students often struggle to identify correlations among various concepts in STEM courses, such as energy, mechanics, and cellular communication. Integrative learning incorporates numerous concepts and subjects to aid understanding and enhance critical thinking. This research describes an integrative learning approach in a General Biology I course where key physics-based concepts that are connected to biological topics were emphasized. In addition, students' knowledge and their beliefs towards biology in all General Biology I classes were assessed using American Association of Colleges and Universities' Integrative Learning Value Rubric and the Colorado Learning Attitudes About Science Survey (CLASS). It was found that correlations existed between students' attitudes towards biology and their overall content knowledge. The results of this study support that integrative learning is a powerful approach to aid in the understanding of physical and biological concepts, leading to improved student success. Vernimisses nondam oriculiciis suam etor avehemus, mei ina, non nesilla L. Nos,
\end{abstract}

\section{KEYWORDS}

Biology, Biophysics, Class, Critical Thinking, Integrative Learning, Physics, SOTL, STEM

\section{INTRODUCTION}

Academicians are concerned with leveraging the curriculum to improve student learning and desire that students display long-term knowledge retention concomitant with applying critical thinking skills to solve problems. In addition, education researchers are continuously exploring which pedagogical approaches are most effective in positively impacting student learning and their attitudes towards learning (Allen et al., 2016; Armbruster et al., 2009; Arthurs \& Kreager, 2017; Reimer et al., 2016; van Kesteren et al., 2016). In science, technology, engineering, and mathematics (STEM), it is an ongoing endeavor to find the best approaches to deliver learning materials to students and the most effective methods to ensure that students will learn and retain the information. One approach is embedding 
integrative learning (IL). Recent evidence supports the idea that enhanced learning occurs when concepts are taught in an integrative manner. Specifically, it is suggested that the circuitry of human memory may be designed to promote the integration of knowledge to foster thorough understanding and better retention over time (van Kesteren et al., 2016). This is of significant importance especially for African Americans who are recognized as being underrepresented in STEM (National Science Foundation, 2015) and do not persist in STEM majors as well as whites (Sasso, 2008). Hence, the purpose of this study was to determine if integrative learning would have a positive impact on African American students' understanding of the content presented in general biology.

The Association of American Colleges \& Universities (AAC\&U) describes integrative learning as "an understanding and a disposition that a student builds across the curriculum and co-curriculum, from making simple connections among ideas and experiences to synthesizing and transferring learning to new, complex situations within and beyond the campus" (Rhodes, 2010). A key finding of the value and importance of integrative learning is that it produces more critical and holistic thinkers as well as better problem-solvers (Labov et al., 2010). It is very ineffective for learners to focus solely on one field of study and not understand the connection to other areas. Integrative learning allows learners to understand the relationship between key concepts in two or more subjects that would sometimes be perceived as unrelated. It also helps individuals connect real-life experiences to a particular subject while envisioning topics in a cohesive manner instead of independently (Berry \& Black, 1987; Sweeney et al., 2015; Walshe et al., 2013).

In a meta-analysis on integrative approaches in STEM education, Becker and Park (2011) conducted research that related to the impact of integrative efforts within STEM, how these efforts vary by grade levels, and how integrative approaches influence student achievement in STEM. These approaches were demonstrated to be most advantageous when multiple STEM disciplines were included. Students who were exposed to various forms of integration that incorporated engineering, mathematics, science and technology were more successful in STEM-related courses and demonstrated a higher level of motivation to study and pursue STEM careers (Becker \& Park 2011).

A plethora of research exists which demonstrates that one of the most effective methods for those teaching physics is to "infuse" learning versus the laborious process of "teaching" physics (Chandra \& Watters, 2012; Holubova, 2008; Jarrett-Thelwell et al., 2019; Karamustafaoglu, 2009; Taber, 2000). Physics is known as a fundamental science; however, many find it very difficult to understand, challenging to learn, and as a result, students often attempt to avoid the subject (Adams et al., 2006; Cziprok, 2011; Fazriyah et al., 2017; Marušić \& Sliško, 2012). Understanding fundamental physics principles is critical for a thorough comprehension of how the world works. Aspects of mechanics and electricity, as well as vectors, forces, work, waves, and energy, are key physics concepts that can easily be integrated into any field. For instance, Park and Liu (2016) conducted a study that assessed students' understanding of energy in various scientific disciplines (i.e., environmental science, biology, chemistry, and physics). This is important because "energy" is often thought of as a distinct concept; however, it is ubiquitous in all science disciplines. Hence, to assess the knowledge of the students, both multiple choice and open-ended justification questions were administered to more thoroughly assess the students' understanding of the material, while also measuring their differentiation of knowledge (Park \& Liu 2016). This study revealed the value of presenting energy in a manner that connects disciplines. The students displayed an improved understanding of energetics and were able to provide more thorough interpretations and experienced an alleviation of difficulty among the sciences.

\section{BACKGROUND OF THE STUDY}

Winston-Salem State University (WSSU) is a Historically Black College and University (HBCU), and almost all students majoring in STEM are African American. Most WSSU students are female and/or first generation. It is reported that $29 \%$ of African American STEM majors drop out of college while $36 \%$ switch to a non-STEM degree (Estrada et al. 2016). In addition, African Americans do 
not persist in STEM majors as well as whites (Charleston et al., 2014; Sasso, 2008; Tsui, 2007) and nationally, although a higher percentage of African American students choose to major in STEM compared to their white counterparts, due to various factors, their attrition rate is greater (National Science Foundation, 2015). These factors include but are not limited to, an inability to transition to college (Museus \& Quaye, 2009), inadequate college preparation (Arcidiacono et al. 2016), selfefficacy beliefs (Lent et al. 2005), and the perception that STEM departments have an unsociable environment (Museus et al., 2008). Hence, we aimed to improve undergraduate STEM education and retain more African American students in their respective majors at WSSU. We hypothesize that using integrative learning in General Biology will lead to enhanced learning of biological principles that are connected to physics.

The goals of this project were (1) to promote a more cohesive understanding of key biological concepts by connecting them to physics via integrative approaches, (2) uncover how students' attitudes towards learning biology correlate with this approach via The Colorado Learning Attitudes about Science Survey (CLASS) (Semsar et al., 2011), and (3) foster student success. The CLASS survey was also used to correlate self-efficacy beliefs with attitudes towards learning biology since it is reported that when students believe in their ability to learn science, they work harder in ensuring they are successful (Shaw \& Barbuti, 2010; Zeldin et al. 2008).

Numerous studies have utilized integrative learning to promote a better understanding of various disciplines (Cziprok \& Miron, 2013; Karamustafaoglu, 2009; Park \& Liu, 2016). In an effort to advance knowledge and encourage a more diverse way of thinking, this study employed an integrated learning approach that was planned, implemented, and assessed in a general biology course. Concepts of energetics, metabolism, cellular communication, and mechanics through a biophysical lens were addressed (Figure 1). While these topics are a part of the curriculum of the course, they were taught by a biophysics professor in an effort to infuse the physical connection to each topic. Since biology is a life science, physics can easily be portrayed through learning about the body from both physical and biological perspectives. This course was selected because many students who learn basic biological concepts have difficulty connecting them to those in other disciplines. In addition, many of the students in this course aspire to matriculate into professional school and/or join the biomedical workforce. As such, it was important to identify physics-related topics that were interconnected with specific topics in introductory biology while having a real-world connection across these disciplines. Importantly, a high percentage of these students must also take physics, which has been a challenging course for them. Thus, the goals of this project were to promote a more cohesive understanding of key biological concepts by connecting them to physics via integrative approaches and identify how students' attitudes and confidence towards learning STEM correlate with integrative learning; this was achieved via The Colorado Learning Attitudes about Science Survey (CLASS), while facilitating student success. The incorporation of CLASS was important as it not only addresses attitudes associated with the sciences, but it is also a part of the Physics Education Technology project. Based on a literature review, this study represents an initial effort in exploring the use and the advantages of integrative learning of introductory physics and general biology. The research study correlates the students' attitudes towards biology, their perceived abilities, and their overall understanding of the material. It is expected that the outcomes of this study will aid in advancing students' knowledge more broadly, and improve STEM retention.

Note: Integrative learning strategies were implemented by using biology and physics concepts. Course planning, implementation of the key concepts, and direct and indirect assessments were used.

\section{METHODS}

\section{Participants}

In the General Biology I classes at WSSU, the majority of the students are female freshmen, as outlined in Table 1; additional information related to classification is also included in this table. This course is 


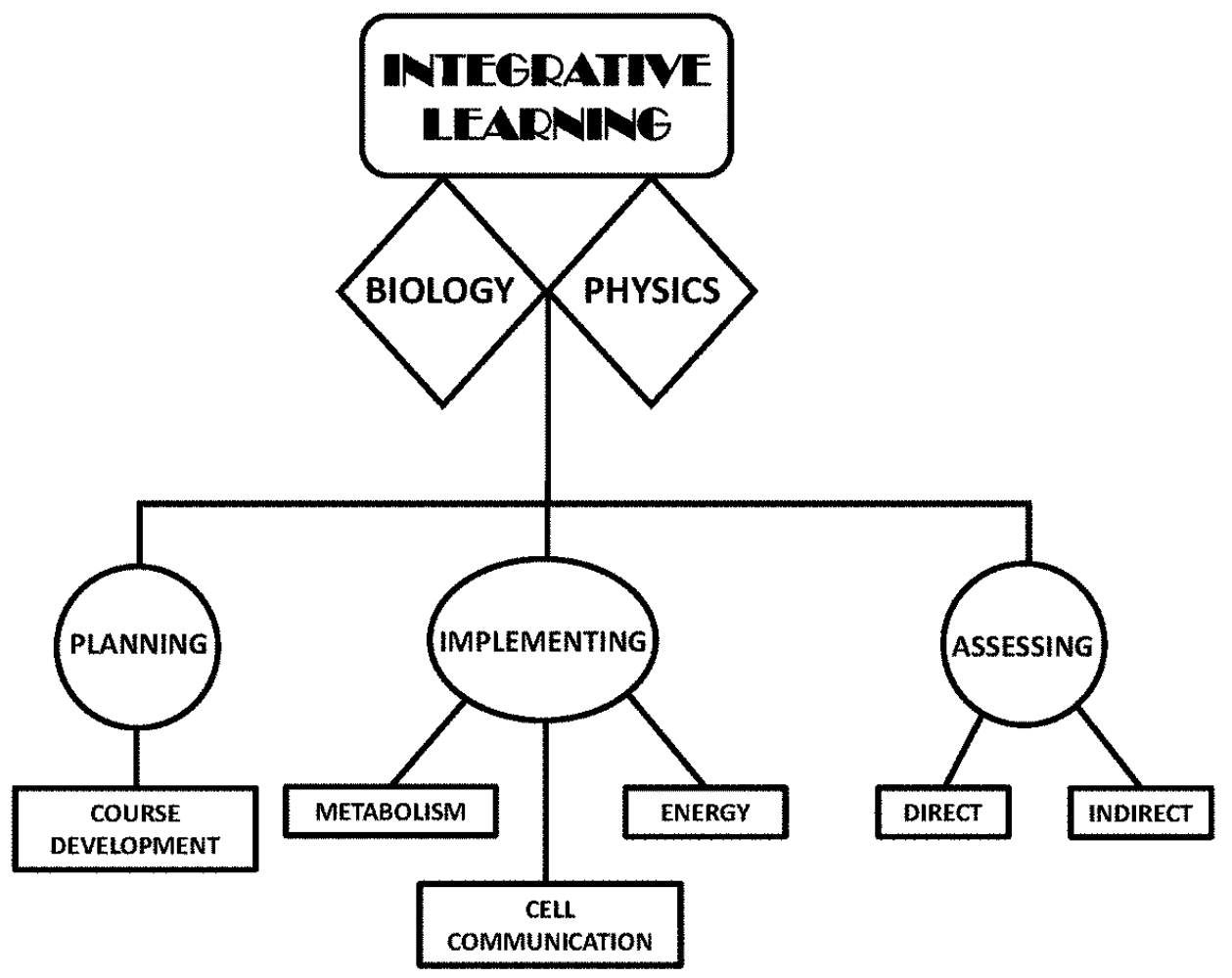

part of the general education curriculum and fulfills the scientific literacy requirement and/or serves as the prerequisite for biology, chemistry, and allied health majors. To implement integrative learning of physics in the General Biology I course, students in two sections participated. One section implemented integrative learning (experimental), while the second was taught in the traditional manner (control). Each assessment was given as a part of an assignment in both the control and experimental sections.

\section{Course Planning}

Using their syllabi, biology and physics faculty selected overlapping topics that were to be taught in the general biology course. Aspects of energetics, metabolism, cellular communication, and mechanics were selected to be the primary focus for further expansion of the distinct connection between biology and physics. Although a common syllabus was used in all sections of this course, the physics professor taught lectures that reinforced the aforementioned areas by emphasizing physical principles to deepen the learning experience and promote thorough understanding. This is best described as an integrative approach (Becker \& Park, 2011).

\section{Course Implementation}

Since many concepts are cross-disciplinary in physics and biology, the concepts of metabolism, cell communication and mechanics, and energy were selected by the physics professor to demonstrate the power of integrative learning in the IL-infused General Biology I lecture. These were chosen because each is critical for concept mastery of general biology. They are also directly correlated with 


\section{General Biology I Courses}

\begin{tabular}{|c|c|c|}
\hline Category & $\begin{array}{c}\text { Traditional } \\
\mathbf{n}=\mathbf{1 3 3}\end{array}$ & $\begin{array}{c}\text { Integrative Learning } \\
\mathbf{n}=\mathbf{1 4 9}\end{array}$ \\
\hline Female & $78 \%$ & $73 \%$ \\
\hline Nursing & $43 \%$ & $46 \%$ \\
\hline Biology & $14 \%$ & $12 \%$ \\
\hline Exercise Science & $5 \%$ & $5 \%$ \\
\hline Psychology & $3 \%$ & $2 \%$ \\
\hline Chemistry & $2 \%$ & $1 \%$ \\
\hline Math & $1 \%$ & $2 \%$ \\
\hline Business & $2 \%$ & - \\
\hline Education & $1 \%$ & $7 \%$ \\
\hline Other allied ealh & $8 \%$ & $4 \%$ \\
\hline Humanities & $4 \%$ & $11 \%$ \\
\hline Undecided & $12 \%$ & $80 \%$ \\
\hline Freshman & $85 \%$ & $17 \%$ \\
\hline Sophomore & $12 \%$ & $2 \%$ \\
\hline Junior & $3 \%$ & $1 \%$ \\
\hline Senior & - & 5 \\
\hline
\end{tabular}

key topics that are discussed in introductory physics. Unfortunately, students often have difficulty understanding these concepts in introductory physics. To address integrative approaches, lectures related to metabolism, cellular communication and mechanics, and energy were given by the physics instructor in the IL section, while the other section of general biology was taught in the traditional manner.

The metabolism lecture described the different types of cellular energy: kinetic, potential, thermal, and chemical energy. As such, the First Law of Thermodynamics (i.e., the conservation of energy), was applied to a boy climbing up a ladder and coming down the slide to demonstrate the connection between kinetic energy (KE) and potential energy (PE). Given the necessary information, students were then asked to quantify both the kinetic energy $\left(\mathrm{KE}=1 / 2 \mathrm{mv}^{2}\right)$ and potential energy $(\mathrm{PE}=\mathrm{mgh})$ of a person climbing a flight of stairs.

To connect biological and physical concepts in the area of cellular communication and mechanics, the biological concepts of active and passive transport were correlated to the physical aspects of natural and violent motion. Homeostasis was also described to help students understand how the cell maintains a stable environment in the midst of changing conditions. Basal and total metabolic rate (traditionally taught as biological concepts) were also used to explain energy conversion (typically taught as a physics concept) at rest and from eating, respectively. In addition, connections to research and diseases (i.e., diabetes, sickle cell disease, HIV, and cancer) were discussed in the IL-infused course. After making connections between biology and physics concepts, in-class discussions were performed that addressed the impact of mechanics on diseases and the detrimental effect of improper energy transfer between cells. 


\section{Direct Assessment}

The students' knowledge of the aforementioned concepts was assessed using short-answer questions and evaluated based on the VALUE rubric from AAC\&U. This rubric was used to determine if ILexposed students had a deeper understanding of biology, as well as the connection between biology and physics compared with students who were taught traditionally. For example, the rubric assesses if connections between disciplines are evident. The students' responses were based on three key aspects of the VALUE Rubric for Integrative Learning (https://www.aacu.org/value/rubrics/integrativelearning): (1) Connections to Experience, (2) Connections to the Discipline, and (3) Integrated Communication. Each category was given a score of 1-4 where "1" represented benchmark, "2-3" denoted milestones, and "4" suggested capstone. The benchmark scale implies that there is some knowledge but a lack of a clear connection, the milestones category denotes that clear connections and explicit knowledge exists and can be effectively explained, and the capstone level suggests a mastery and deepened understanding of information.

Using the Integrative Learning VALUE Rubric, the following embedded test questions were used to evaluate students' knowledge of biology, and their ability to connect biology and physics:

1. In 2-3 complete sentences, explain what happens to the movement of cells within the body when the body temperature is abnormal.

2. Clearly describe the differences between active vs. passive transport, and address the role of energy for each type.

An additional approach to directly assess students' understanding of information was through a set of multiple-choice questions. The following questions were given to each student in both the General Biology I section that had a traditional lecture as well as the section that incorporated integrative learning. The three multiple-choice questions were graded based on the total number that were correct, and a letter grade of A through $\mathrm{F}$ was assigned for these and additional multiple choice questions.

1. Carbohydrates, fats, proteins and water represent nearly all of the weight of food. Which of the following has the greatest food energy per mass?
a. Carbohydrates
b. Fats
c. Proteins
d. Water

2. Which best describes the $1^{\text {st }}$ law of thermodynamics?
a. Energy is changed from one form to another with a loss of usable energy.
b. Energy is not created nor destroyed, but it can change from one energy form to another.
c. Energy can be created from matter or used to produce matter.
d. Some useful energy is lost as heat whenever an energy transfer occurs.

3. The higher the temperature,

a. The slower the speed of molecular movement

b. The faster the speed of molecular movement

c. The speed is a constant

d. The speed of the molecular movement is random

\section{Indirect Assessment}

Perceived self-confidence relates to a person's belief about their capabilities that translates into their ability to perform and impacts their lives. How people feel, think, motivate themselves, and behave are related to these beliefs and affect their cognitive, motivational, emotional, and selection processes 
(Bandura, 1994). Psychological factors such as self-confidence beliefs and science identity (Chemers et al., 2011; Flowers et al., 2011) are known to influence the retention and graduation rates of STEM majors; such mediators must be considered when designing interventions that assist students pursuing a STEM career. Since students' classroom experiences help shape their beliefs, it is critical that educators deliver content and design activities that complement learning and encourage persistence in STEM. The Colorado Learning Attitudes about Science Survey (CLASS) is a validated instrument that helps STEM educators assess their students' views about science and their cognitive abilities (https://www.colorado.edu/sei/class/). Currently, it is designed for biology (Knight \& Smith, 2010), chemistry (Heredia \& Lewis, 2012), or physics majors (Perkins et al., 2005; Brewe et al., 2013). At WSSU, it was administered to the General Biology I students ( $\mathrm{n}=198)$, and IL-exposed students' responses were compared to those taught in a traditional manner. A five-point Likert scale was used to ask 31 questions and addressed (1) real world connection, (2) problem-solving difficulty, (3) enjoyment, (4) problem-solving effort, (5) conceptual connections/memorization, (6) problem-solving difficulty, (7) reasoning, and (8) questions that did not fit into any category. In addition to the eight categories of the CLASS, another category was developed to address self-confidence (Table 2). Although self-confidence is not a specific category, statements such as, "If I get stuck on answering a biology question on my first try, I usually try to figure out a different way that works" are useful in determining students' self-efficacy beliefs. For validation, one statement, \#28, purposely asks the students to choose "agree"; this ensures an $80 \%$ chance of identifying students who are not reading the statements and are choosing answers at random. Thus, surveys were omitted when students did not choose "agree" as the response.

\section{Data Analysis}

Chi-square tests were used to show a comparative analysis of the data collected for the traditional versus the integrative learning sections of General Biology I for both the indirect (CLASS data) assessment and the direct assessment of the multiple-choice questions. The CLASS data were further analyzed using the Z-test (Zaykin, 2011) to compare the responses of the control (traditional) to the experimental (IL-exposed) group. A Z-test is used to test a set of hypotheses for a single proportion or a difference of proportions to generate accurate results. Due to the large sample size $(n>30)$, the Z-test was used to compare the two sections of general biology. Our discussions will be based on the results of the two-sample Z-test by setting $\mathrm{z}$ to 0.025 and using the equation below ( $\mathrm{p}=$ percentage, $\mathrm{T}=$ traditional, $\mathrm{IT}=$ integrative thinking, $\mathrm{n}=$ sample size):

$$
\hat{P}_{T}-\hat{P}_{l T} \pm z_{.025} \sqrt{\frac{\hat{P_{T}\left(1-\hat{P}_{T}\right)}}{n_{T}}-\frac{\hat{P}_{T}\left(1-\hat{P}_{l T}\right)}{n_{l T}}}
$$

\section{RESULTS}

\section{Direct Assessment: Multiple Choice Questions}

At the end of the semester, students in the course measuring integrative learning (IL-infused) and the traditional course were given a total of three multiple choice questions as a direct assessment of the knowledge gained related to metabolism, energy, and mechanics. These questions were evaluated based on accuracy, and letter grades were assigned. From Figure 2, the section that incorporated integrative learning showed a statistically significant improvement in grades of $\mathrm{C}$ or better in comparison to the 


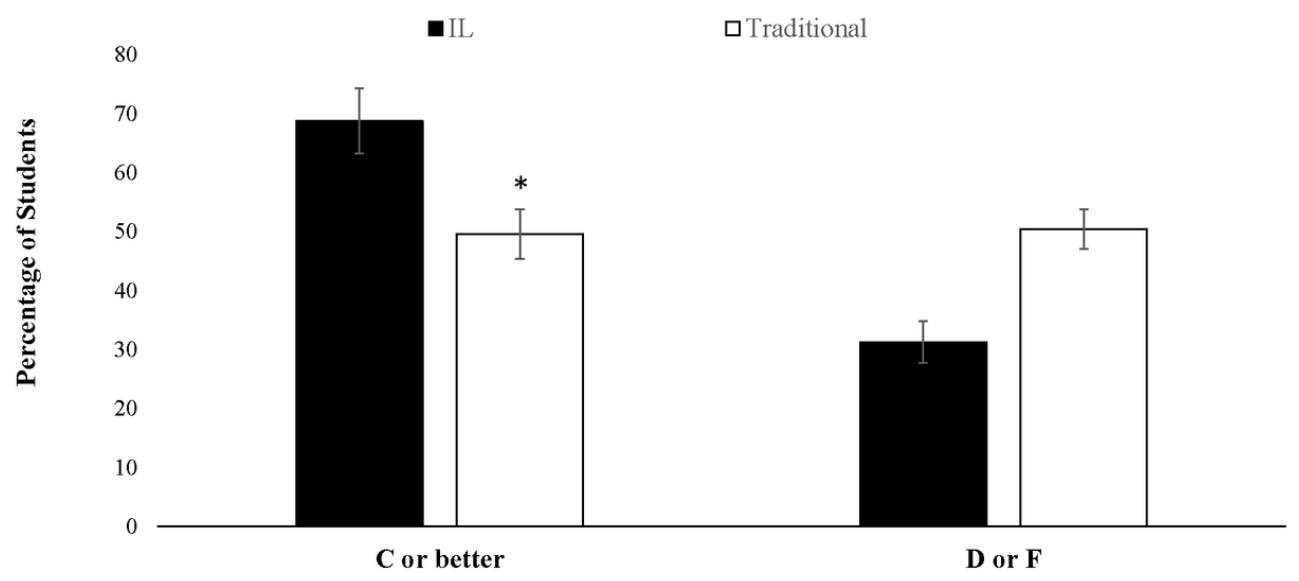

a D or F in the integrative learning course was substantially lower by roughly $45 \%$ with respect to the individuals that scored a $\mathrm{C}$ or better.

\section{Direct Assessment: Open-Ended Questions}

Students were given two open-ended questions to determine the level of depth of the students' ability to synthesize, explain, and connect information across physics and biology. Each question was evaluated based on three primary categories from the AAC\&U VALUE Rubric for integrative learning: (1) Connections to Experience; (2) Connections to Discipline; and (3) Integrated Communication. Within each category, students demonstrated various levels of performance such as capstone (level 4), milestone (level 2 or 3), benchmark (level 1), or not meeting the standards (level 0). With respect to the Connections to Experience, $68 \%$ of the students in the integrative learning course scored within the milestone level in comparison to $51 \%(\mathrm{p}<0.001)$ for the students in the traditionally taught course (Figure 3A). This information suggests that the IL cohort was able to more adequately associate life experiences with the concepts and knowledge gained. What is most interesting is that the majority of the students in both sections of general biology were able to make some connection to real-life examples according to the benchmark level; however, there is a 2.3 fold increase of the students in the traditional lecture that lack the capability to provide more thorough explanations as compared to the IL cohort. Figure 3B shows that when measuring the Connections to Discipline, 59\% of the students in the IL compared to $13 \%$ in the traditional course were able to correlate examples and facts to other disciplines when asked $(\mathrm{p}<0.001)$; this falls in the category of milestone-level 2 . However, roughly $19 \%$ of students were able to make connections independently in the IL course, which was nearly $50 \%$ higher than the section that utilized traditional instruction $(\mathrm{p}<0.001)$. It is important to note that $78 \%$ of the individuals in the traditionally taught course were able to answer each question to the benchmark level; however, the students' seemed to lack the ability to provide explicit detail when addressing Integrated Communication (Figure 3C).

\section{Indirect Assessment: CLASS Instrument}

As mentioned previously, statements on the CLASS Survey were divided into eight categories: (1) real world connection, (2) problem-solving difficulty, (3) enjoyment, (4) problem-solving effort, (5) conceptual connections/memorization, (6) problem-solving difficulty, (7) reasoning, and (8) questions that did not fit into any category, as outlined in Table 2. For example, \#29 states, "The general public misunderstands many biological ideas," and at best, can be grouped under real world connections; 

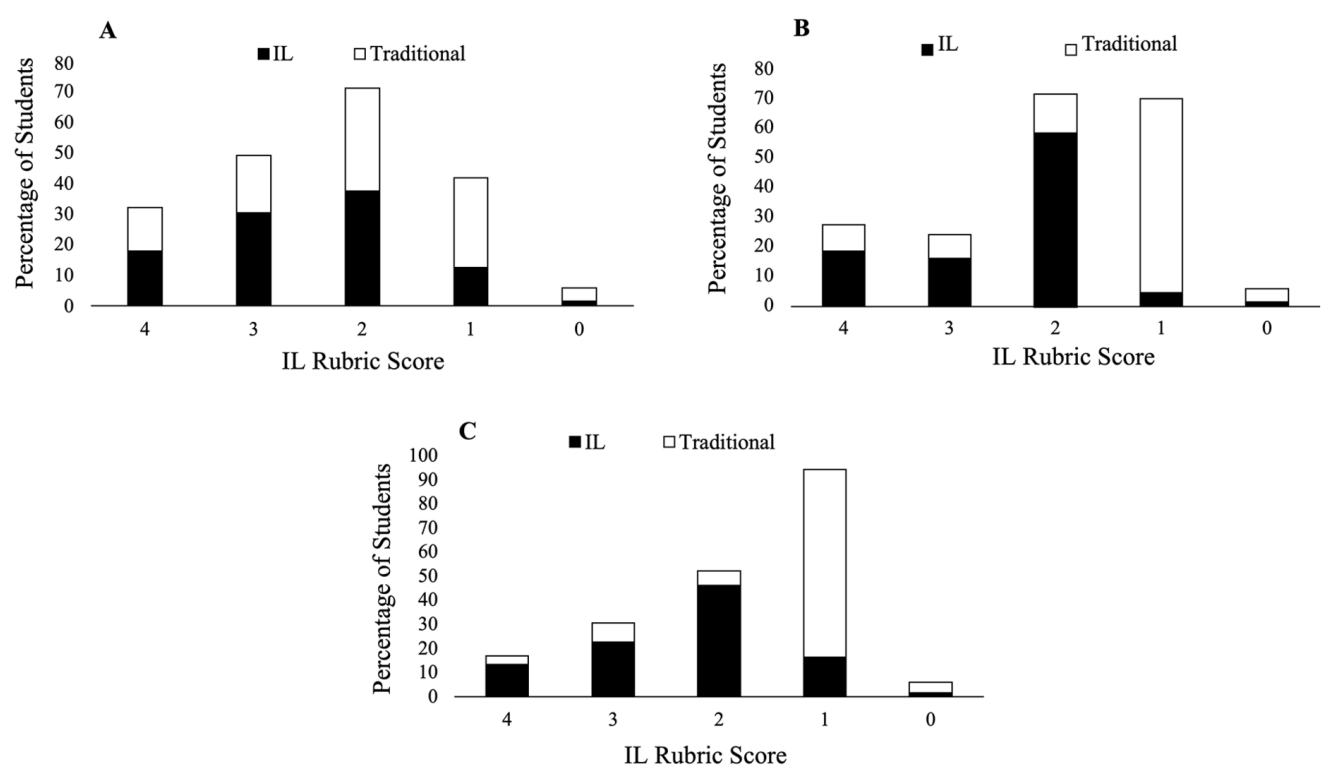

however, it is difficult to draw definite conclusions based on student responses. In addition, some questions fell under more than one category; \#12, "I enjoy figuring out answers to biology questions," was assessed under real world connections, enjoyment, and problem-solving effort. Hence, analyses will take all of this into account when assessing all student responses. Importantly, it is well known that self-confidence beliefs and performance are highly correlated; hence the authors felt strongly that a ninth category be added to address this. Especially since most WSSU students are AfricanAmerican and have not been retained as STEM majors at the same level as their white counterparts. As formerly stated, students' self-confidence beliefs are important when addressing retention and success, especially in STEM. It is noteworthy to comment that researchers at Florida International University, a Hispanic-Serving Institution (HSI) also linked self-confidence to some of the statements in the CLASS instrument (Brewe et al., 2013).

Table 2. Class categories and corresponding questions

\begin{tabular}{|l|l|}
\hline \multicolumn{1}{|c|}{ Categories } & \multicolumn{1}{c|}{ Statement \# } \\
\hline Real World Connection & $2,12,14,16,17,19,25$ \\
\hline Problem-solving Difficulty & $3,5,6,10,11,21,30$ \\
\hline Enjoyment & $1,2,9,12,18,27$ \\
\hline Problem-solving Effort & $8,12,20,22,24,27,30$ \\
\hline Conceptual Connections/ Memorization & $6,8,11,15,19,23,31,32$ \\
\hline Problem-solving strategies & $7,8,20,22$ \\
\hline Reasoning & $8,14,16,17,24$ \\
\hline Uncategorized statements (All). & $4,13,26,29$ \\
\hline Self-efficacy & $8,10,20,21,22,24,30$ \\
\hline
\end{tabular}


For simplicity and clarity, rather than use all five choices of the Likert scale, strongly disagree and disagree were grouped together, as was strongly agree and agree; neutral remained alone. Strongly disagree was denoted by " 1 ", neutral was represented by " 3 ", and strongly agree was denoted by " 5 ". Hence, the results are discussed based on three choices. Table 3 provides a set of descriptive statistics of CLASS data, whereas Table 4 demonstrates Z-test analyses of the CLASS data. The significance was determined for each question to see if the IL-exposed students had better outcomes than those who were in the traditional section (Zaykin, 2011).

Real-World Connection. When asked to respond to whether learning biology changes their ideas about how the natural world works, the IL and traditional cohort showed no difference, they both thought similarly (Figure 4). The IL-exposed students thought about biology in their everyday lives to a greater degree $v s$. their traditional counterparts by a factor of $1.7(\mathrm{p}<0.050)$, but they did not enjoy answering biological questions as much as the traditional students $(\mathrm{p}<0.010)$ by a factor of 1.5 (Table 3). The IL cohort felt it was a valuable use of their time to study biological experiments compared to the traditional group by a factor of 1.4 but this was not statistically significant. This was also the case when asked if their real-world experiences related to biology (Table 3). The IL group was only 1.2 times in agreement vs. the traditional. Also of significance was Question 25 that addressed the importance of human health; the IL cohort was only 1.3 times more likely to underscore this importance versus the traditional. This question is also highly skewed for the traditional versus the IL cohort (Table 3).

Note: An average of the CLASS results for both the IL and Traditional courses were determined ( $n=89$ for IL and $n=33$ for Traditional). An additional category of self-confidence was assessed. Error bars reflect the standard error of the mean.

Problem-Solving Difficulty. As demonstrated in Table 3, the students in the IL-exposed class expected the rules of biological principles to help them understand ideas by a factor of 1.5 compared to the control $(\mathrm{p}<0.010)$; they were also 1.2 times more likely to believe they had the ability to solve a problem even if they could not remember an approach $(\mathrm{p}<0.050)$. Moreover, they were 1.6 times more likely to believe that biological methods and ideas were transferable to dissimilar problems ( $\mathrm{p}<0.010$ ). Statement \#30, "I do not spend more than a few minutes stuck on a biology question before giving up or seeking help from someone else", actually addresses two different actions, giving up altogether $v s$. seeking help to solve the problem. Hence, the former refers to a student's sense of hopelessness while the latter addresses the students' ability to seek help when needed, which is favorable.

Enjoyment. Comparing the IL-infused to the traditional section, there was a marked lack of enjoyment towards biology (Figure 4). The differences were noteworthy. The IL-exposed students were 1.5-2.0 times less likely to express an enjoyment for biology. Most stated they were not taking the course due to curiosity ( $\mathrm{p}<0.001)$, did not care to make a contribution to society $(\mathrm{p}<0.001)$, did not enjoy solving biological problems $(\mathrm{p}<0.010)$, nor would they have taken the course for the "fun" of it $(\mathrm{p}<0.05)$.

Problem-Solving Effort. As stated previously, when asked if they enjoyed answering biological questions, the traditional cohort was 1.5 times more likely to agree with this statement, as highlighted in Table 3. The experimental cohort was 2.0 times more likely to agree with the statement, "When studying biology, I relate the important information to what I already know rather than just memorizing it the way it is presented," an indication that they perceived they were making more connections than the control group $(\mathrm{p}<0.001)$. When asked to respond to their approach to solving biological questions, the IL-exposed group perceived that they were more likely to use more than one method $v s$. the control group by a factor of $2.0(\mathrm{p}<0.001)$.

Conceptual Connections/Memorization. It was clear that the IL-exposed students were 1.5 times more likely to believe that biological rules aid in their understanding $(\mathrm{p}<0.050), 1.6$ times more likely to believe in transferring strategies when solving problems $(\mathrm{p}<0.010)$, and 1.3 times less likely to agree that biology comprises memorizing facts and not about investigation $(\mathrm{p}<0.050)$. This cohort 
Table 3. Descriptive statistics of CLASS data

\begin{tabular}{|c|c|c|c|c|c|c|c|c|c|}
\hline \multirow[t]{2}{*}{ Question } & \multicolumn{2}{|r|}{ Mean } & \multicolumn{2}{|c|}{$\begin{array}{l}\text { Standard } \\
\text { Deviation }\end{array}$} & \multicolumn{2}{|c|}{ Skewness } & \multicolumn{2}{|c|}{ Kurtosis } & \multirow[t]{2}{*}{ p values } \\
\hline & $\mathrm{IL}^{\mathrm{a}, \mathrm{c}}$ & Traditional $^{\mathrm{b}, \mathrm{c}}$ & $\mathrm{IL}^{\mathrm{a}}$ & Traditional $^{\mathrm{b}}$ & $\mathrm{IL}^{\mathrm{a}}$ & Traditional $^{\mathrm{b}}$ & $\mathrm{IL}^{\mathrm{a}}$ & Traditional $^{\mathrm{b}}$ & \\
\hline 1 & 2.76 & 2.61 & 1.16 & 1.09 & -0.017 & 0.253 & -0.853 & -0.119 & $1.89 \mathrm{E}-6^{*}$ \\
\hline 2 & 2.71 & 3.001 & 1.08 & 1.12 & 0.444 & -0.143 & -0.257 & -0.890 & 0.0443 \\
\hline 3 & 2.96 & 3.12 & 1.22 & 1.11 & 0.0113 & -0.107 & -1.10 & -0.864 & $5.27 \mathrm{E}-02$ \\
\hline 4 & 2.49 & 2.58 & 0.983 & 1.17 & 0.218 & 0.424 & -0.341 & -0.672 & $9.06 \mathrm{E}-6^{*}$ \\
\hline 5 & 2.72 & 3.30 & 1.31 & 1.29 & 0.261 & -0.235 & -1.101 & -1.04 & 0.168 \\
\hline 6 & 2.17 & 2.58 & 0.829 & 0.902 & 0.286 & 0.167 & -0.447 & -0.743 & $2.79 \mathrm{E}-3 *$ \\
\hline 7 & 3.21 & 3.21 & 1.06 & 1.14 & -0.324 & -0.579 & -0.486 & -0.759 & $5.57 \mathrm{E}-5^{*}$ \\
\hline 8 & 3.93 & 3.79 & 0.671 & 1.02 & -0.846 & -1.41 & 1.76 & 2.04 & $5.30 \mathrm{E}-02$ \\
\hline 9 & 2.93 & 2.91 & 1.26 & 1.10 & -0.115 & 0.0396 & -1.02 & -0.172 & $2.49 \mathrm{E}-6^{*}$ \\
\hline 10 & 3.16 & 3.24 & 1.02 & 1.06 & -0.0618 & -0.186 & -0.557 & -0.226 & 0.0250 \\
\hline 11 & 3.34 & 3.24 & 0.929 & 1.17 & -0.728 & -0.628 & 0.506 & -0.441 & 0.0257 \\
\hline 12 & 3.15 & 2.70 & 1.15 & 1.31 & -0.519 & 0.072 & -0.549 & -1.04 & $2.76 \mathrm{E}-3 *$ \\
\hline 13 & 3.55 & 3.61 & 0.853 & 1.03 & -0.330 & -0.395 & 0.599 & -0.133 & 0.795 \\
\hline 14 & 3.67 & 3.42 & 1.02 & 0.969 & -0.355 & -0.759 & -0.684 & 0.872 & 0.413 \\
\hline 15 & 2.74 & 2.27 & 1.37 & 1.07 & 0.183 & 0.884 & -1.23 & 0.140 & $2.94 \mathrm{E}-5^{*}$ \\
\hline 16 & 3.64 & 3.55 & 0.819 & 1.12 & -0.516 & -0.546 & 0.481 & -0.105 & 0.150 \\
\hline 17 & 3.30 & 3.42 & 1.01 & 1.23 & -0.291 & -0.573 & -0.331 & -0.181 & 0.190 \\
\hline 18 & 2.22 & 2.48 & 1.25 & 1.28 & 0.688 & 0.419 & -0.645 & -0.678 & $2.25 \mathrm{E}-3^{*}$ \\
\hline 19 & 2.36 & 2.24 & 0.899 & 1.06 & 0.178 & 0.648 & -0.685 & -0.0204 & 0.125 \\
\hline 20 & 3.48 & 3.24 & 0.897 & 1.06 & -0.518 & -0.019 & 0.139 & -0.755 & $4.93 \mathrm{E}-4 *$ \\
\hline 21 & 2.39 & 2.64 & 0.996 & 0.929 & 1.04 & 1.07 & 0.887 & 0.889 & $9.44 \mathrm{E}-3^{*}$ \\
\hline 22 & 3.69 & 3.55 & 0.887 & 1.00 & -0.432 & -0.726 & 0.0320 & 0.934 & $4.34 \mathrm{E}-4^{*}$ \\
\hline 23 & 2.37 & 2.45 & 0.946 & 1.00 & 0.424 & 0.924 & -0.332 & 0.975 & $1.00 \mathrm{E}-3^{*}$ \\
\hline 24 & 3.27 & 3.42 & 0.914 & 1.03 & -0.384 & -0.602 & -0.131 & 0.286 & 0.526 \\
\hline 25 & 2.40 & 2.09 & 0.962 & 1.13 & 0.435 & 1.06 & -0.096 & 0.847 & 0.148 \\
\hline 26 & 2.97 & 3.36 & 1.03 & 0.962 & 0.0686 & -0.146 & -0.515 & 0.0201 & $3.26 \mathrm{E}-3^{*}$ \\
\hline 27 & 2.94 & 2.82 & 1.14 & 1.18 & -0.122 & 0.0139 & -0.690 & -0.976 & 0.521 \\
\hline 29 & 3.55 & 3.48 & 0.929 & 0.939 & -0.194 & -1.16 & -0.397 & 1.45 & $1.57 \mathrm{E}-4^{*}$ \\
\hline 30 & 2.63 & 2.94 & 1.02 & 0.998 & 0.472 & 0.328 & -0.298 & -0.656 & 0.241 \\
\hline 31 & 2.6 & 2.27 & 0.950 & 0.761 & 0.167 & 0.389 & -0.276 & 0.167 & $\begin{array}{c}5.68 \mathrm{E}- \\
10^{*}\end{array}$ \\
\hline 32 & 2.96 & 2.78 & 0.993 & 1.07 & 0.296 & -0.039 & -0.251 & -0.756 & 0.0240 \\
\hline
\end{tabular}


Figure 4. Indirect assessment of integrative learning using CLASS.

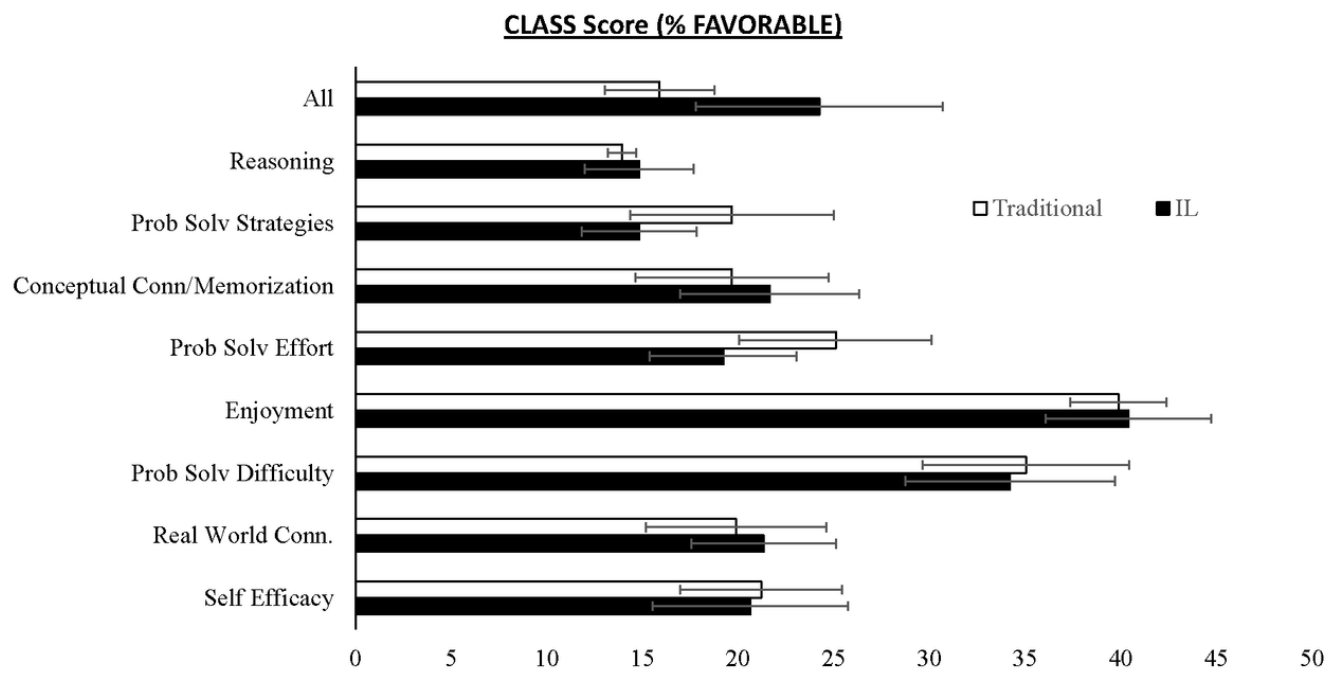

received a lecture about the impact of mechanics on disease, specifically, HIV, sickle cell, diabetes, and cancer. Thus, it suggests that they understand the value of biological research.

Problem-Solving Strategies. Although more students in the traditional class believed that if they get stuck when solving a problem, they could find another way compared to the IL-exposed group by a factor of $1.5(\mathrm{p}=0.050)$, the IL-exposed students appeared to see the connection between biology and their personal lives $(p<0.001)$. Furthermore, this cohort believed that they could solve a problem on an exam using more than one method $(\mathrm{p}<0.050)$, that there is more than one way to solve a problem $(\mathrm{p}<0.001)$, and that they could study biology by making connections to what they already know $(\mathrm{p}<0.001)$.

Reasoning. Surprisingly, Figure 4 and Table 3 demonstrate that the groups showed no statisticallysignificant difference in their statements related to reasoning in biology. However, a slight difference was seen with statements related to taking extra time to figure out a problem i.e., traditional students were twice as likely to agree with doing this $v s$. the IL-exposed students. Overall, most students, regardless of cohort, were neutral or did not care to spend extra time on solving biological problems (Table 4).

Uncategorized Statements. Statements \#4 and \#26 refer to connections within biology and mathematics. The IL-exposed students believed more in this connection compared to the traditional cohort by a factor of 2.4 ( $\mathrm{p}<0.001$ and 0.01 , respectively). It can be debated that these actually fall under the conceptual connection category. Statistical significance was not seen for statement \#13, which connected biology to the government. Significance was seen with the beliefs of the IL-exposed students, they displayed less confidence in the general public's knowledge of biological ideas (Table 3 ).

Self-Confidence Related Statements. The authors believed that statements 8, 10, 20, 21, 22, and 24 , are indications of self-confidence (Table 2). Table 3 displays that the responses to Questions 8 and 21 from the traditional cohort are highly skewed when compared to the IL cohort. The control group superseded the IL-taught class by a factor of two when it relates to believing they could solve a problem and having more than one way to come to a solution. This group also believed in continuously working on a problem until a solution is found more than the IL cohort $(\mathrm{p}<0.01)$. Both 
Table 4. Z-test analyses CLASS data

\begin{tabular}{|c|c|c|c|c|c|c|}
\hline Question & $\mathbf{A} / \mathbf{S A}$ & $\begin{array}{l}(-) \\
\mathbf{N}\end{array}$ & D/SD & $\mathbf{A} / \mathbf{S A}$ & $\begin{array}{l}(+) \\
\mathbf{N}\end{array}$ & D/SD \\
\hline 1 & -0.55 & -0.1 & -0.17 & -0.23 & 0.29 & 0.23 \\
\hline 2 & 0.01 & -0.27 & -0.29 & 0.38 & 0.08 & 0.1 \\
\hline 3 & -0.17 & -0.12 & -0.27 & 0.23 & 0.22 & 0.11 \\
\hline 4 & -0.06 & -0.32 & -0.15 & 0.27 & 0.02 & 0.25 \\
\hline 5 & -0.03 & -0.14 & -0.38 & 0.37 & 0.18 & 0.0 \\
\hline 6 & -0.01 & -0.15 & -0.36 & 0.27 & 0.22 & 0.04 \\
\hline 7 & -0.09 & -0.32 & -0.12 & 0.31 & -0.01 & 0.24 \\
\hline 8 & -0.2 & -0.15 & -0.04 & 0.12 & 0.09 & 0.2 \\
\hline 9 & -0.31 & -0.01 & -0.24 & 0.05 & 0.38 & 0.13 \\
\hline 10 & -0.18 & -0.15 & -0.22 & 0.21 & 0.24 & 0.11 \\
\hline 11 & -0.17 & -0.31 & -0.07 & 0.23 & 0.05 & 0.26 \\
\hline 12 & -0.36 & -0.16 & -0.04 & 0.01 & 0.22 & 0.34 \\
\hline 13 & -0.17 & -0.27 & -0.07 & 0.23 & 0.11 & 0.18 \\
\hline 14 & -0.28 & -0.08 & -0.16 & 0.12 & 0.29 & 0.11 \\
\hline 15 & -0.32 & -0.23 & 0.07 & 0.01 & 0.03 & 0.44 \\
\hline 16 & -0.26 & -0.18 & -0.06 & 0.14 & 0.18 & 0.21 \\
\hline 17 & -0.15 & -0.17 & -0.2 & 0.25 & 0.22 & 0.1 \\
\hline 18 & -0.15 & -0.04 & -0.33 & 0.16 & 0.32 & 0.07 \\
\hline 19 & -0.12 & -0.24 & -0.13 & 0.14 & 0.11 & 0.26 \\
\hline 20 & -0.31 & -0.2 & -0.03 & 0.08 & 0.17 & 0.31 \\
\hline 21 & -0.12 & -0.06 & -0.32 & 0.16 & 0.29 & 0.07 \\
\hline 22 & -0.27 & -0.12 & -0.11 & 0.13 & 0.26 & 0.12 \\
\hline 23 & -0.15 & -0.16 & -0.2 & 0.12 & 0.19 & 0.19 \\
\hline 24 & -0.12 & -0.23 & -0.19 & 0.28 & 0.15 & 0.11 \\
\hline 25 & -0.15 & -0.26 & -0.06 & 0.09 & 0.08 & 0.31 \\
\hline 26 & -0.07 & -0.13 & -0.34 & 0.31 & 0.26 & -0.03 \\
\hline 27 & -0.18 & -0.28 & -0.1 & 0.2 & 0.07 & 0.29 \\
\hline 28 & -0.09 & 0.0 & -0.03 & 0.03 & 0.0 & 0.09 \\
\hline 29 & -0.12 & -0.26 & -0.13 & 0.27 & 0.11 & 0.13 \\
\hline 30 & -0.08 & -0.16 & -0.32 & 0.28 & 0.2 & 0.07 \\
\hline 31 & -0.21 & -0.29 & 0.01 & 0.01 & 0.07 & 0.4 \\
\hline 32 & -0.15 & -0.28 & -0.12 & 0.2 & 0.1 & 0.27 \\
\hline
\end{tabular}


groups believed that if it was impossible to remember a specific approach for an exam, they should just give up. The IL group believed more than the traditional group by a factor of 1.5 that they can figure out a difficult problem through accessing prior knowledge $(\mathrm{p}<0.001)$.

\section{DISCUSSION}

This work presents a distinctive way to infuse integrative learning into the introductory biology curriculum, while incorporating specific aspects of physics. There is no question that a student's perception impacts their learning; however, the level of exposure to connected topics is proportional to student understanding and success (Chamany et al., 2008; Nehm, 2019). This is clearly demonstrated by both the CLASS and the direct assessment of the overall student outcomes. In general, students in the section that used integrative learning as a strategy usually gave more favorable responses to the CLASS statements. They definitely gave more auspicious responses when measuring conceptual connection/memorization and problem-solving difficulty.

When correlating the open-ended answers scored using the VALUE rubric to the CLASS survey, the IL-exposed students scored mostly in the capstone and milestone range, and outperformed the control group. Unfortunately, the majority of the traditional students did not surpass benchmark. This correlates to the CLASS survey category for conceptual connections/memorization, but not with real world connections. As freshman, their knowledge base may not be extensive enough to see biology in the world around them (Semsar et al. 2011). Thus, they display a knowledge of conceptual, but not real-world connections (AAAS, 2011; Hewitt et al., 2019). When individual CLASS categories are correlated with the multiple-choice questions, it is evident that the real-world connections and conceptual connections/memorizations responses align with the grades given such that the IL group fared better than the control cohort.

Integrative learning is a cost-effective and innovative way to enhance student learning on campus. It can also unify faculty across disciplines and minimize silos, while promoting cross-disciplinary thinking and student success (D'Souza et al., 2016). Having both open-ended questions, as well as multiple choice questions for the direct assessment supports previous work from McDermott (1984) regarding understanding of key basic concepts (McDermott et al., 1984). It is hoped that students' exposure to this level of thinking will improve their ability to retain information, while also being able to easily digest concepts that they have previously studied as they matriculate as an undergraduate.

\section{CONCLUSION}

Integrative learning has been demonstrated to be an effective approach to broaden and enhance learning, ultimately leading to more diverse thinkers and problem-solvers. A comparative study to understand the impact of integrative learning into the General Biology curriculum was explored in an effort to provide a better understanding of biological concepts, using both direct and indirect assessments. Data from both traditional and integrative learning-based introductory biology courses were collected. Direct assessments accounted for specific content related to energy, mechanics, and thermodynamics; this was achieved by addressing specific questions and definitely answers were accounted for. Through these direct measures, students within the IL-based course proved to have greater success (via higher grades) in the content knowledge, as well as being able to make a better connection to real-life scenarios in comparison to the students that were in the course that was taught traditionally. Indirect assessments were related to students' beliefs and attitudes towards learning, which was attained by using the CLASS. The incorporation of CLASS was important as it not only addresses attitudes that are associated with the sciences, but it is also a part of the Physics Education Technology project. The indirect measurements demonstrated that students in the IL-based course had more self-confidence and self-efficacy. This is important to note because people tend to be more successful and have a greater mastery of information in environments where they exhibit 
more confidence. The importance is magnified when teaching African American students whose underrepresentation in STEM has been problematic for decades and using the IL-infused approach has led to enhanced understanding for this cohort. This is one way to help underrepresented students persist in STEM.

Limitations to this study exist. Statement \#28 instructed students to answer "D" as a choice; hence, because only 33 surveys from the traditional section had this marked, they were the only ones counted. Hence, the sample size was smaller than expected and it could be argued that students in the traditional section who answered "D" correctly outscored the IL class because the answers of the more attentive students were captured. There were questions that did not appear to fit into the specified categories. However, \#4 refers to biology having disconnected topics and \#26 relates to mathematical connections; these statements may fall under conceptual connections. Statements \#13 and \#29 can be categorized under the real-world connection category. Since the instrument is validated to have these as "stand alone" statements, the data from them were addressed as their own distinctive category. Another limitation is related to the open-ended questions. Students who left them blank caused some scores to fall below the benchmark (Figure 3). Thus, correlations of these questions to the CLASS survey are not as robust. Finally, self-confidence was difficult to assess based on the responses from both cohorts and given most were freshman. Contrary to the expected results, the measures of self-confidence were similar for both the IL and traditional groups. Based on the direct assessment, it was expected that the students in the IL group would be more self-efficacious. Also, it was thought that a deeper understanding would cause the students to be more self-efficacious after utilizing the integrative approaches. In the future, a longitudinal study will be performed to compare all student classifications and assess differences.

\section{ACKNOWLEDGMENT}

We would like to thank Drs. Louise Allen, Stephanie Dance-Barnes, and Cheraton Love for assisting with administering the CLASS in their sections of General Biology I, and Dr. Ronald Patterson (statistician, WSSU) for providing assistance with CLASS survey statistical analyses. In addition, we appreciate the invaluable assistance of Drs. Anthony DePass (biologist, Long Island University), Njema Frazier (physicist, Department of Energy) and Katie McGraw (grants specialist, Chicago School of Psychology) for providing feedback related to this manuscript. We would be remiss if we failed to especially thank Drs. Kelly Mack (AAC\&U), Alma Clayton-Pederson (AAC\&U), and Claudia Rankins (NSF) for their scholarly insight, support, and providing faculty development opportunities for us to flourish. This project was generously supported by the National Science Foundation HBCU UP Program (NSF ID 1235727). Any opinions, findings, conclusions, or recommendations expressed in this material are those of the authors and do not necessarily reflect the views of the National Science Foundation. 


\section{REFERENCES}

AAAS. (2011). Vision and change in undergraduate biology education: A call to action. AAAS.

Adams, W., Perkins, K., Podolefsky, N., Dubson, M., Finkelstein, N., \& Wieman, C. (2006). New instrument for measuring student beliefs about physics and learning physics: The Colorado Learning Attitudes about Science Survey. Physical Review. Physics Education Research, 2, 1-14.

Allen, M., Webb, A. W., \& Matthews, C. E. (2016). Adaptive teaching in STEM: Characteristics for effectiveness. Theory into Practice, 55(3), 217-224. doi:10.1080/00405841.2016.1173994

Arcidiacono, P., Aucejo, E. M., \& Hotz, V. J. (2016). University differences in the graduation of minorities in STEM fields: Evidence from California. The American Economic Review, 106(3), 525-562. doi:10.1257/ aer.20130626 PMID:31371833

Armbruster, P., Patel, M., Johnson, E., \& Weiss, M. (2009). Active learning and student-centered pedagogy improve student attitudes and performance in introductory biology. CBE Life Sciences Education, 8(3), $203-213$. doi:10.1187/cbe.09-03-0025 PMID:19723815

Arthurs, L. A., \& Kreager, B. Z. (2017). An integrative review of in-class activities that enable active learning in college science classroom settings. International Journal of Science Education, 39(15), 2073-2091. doi:10 $.1080 / 09500693.2017 .1363925$

Bandura, A. (1994). Self-efficacy. In V. S. Ramachaudran (Ed.), Encyclopedia of human behavior (Vol. 4, pp. 71-81). Academic Press.

Barbera, J., Adams, W., Wieman, C., \& Perkins, K. (2008). Modifying and validating the Colorado Learning Attitudes about Science Survey for use in chemistry. Journal of Chemical Education, 85(10), 1435-1439. doi:10.1021/ed085p1435

Becker, K., \& Park, K. (2011). Effects of integrative approaches among science, technology, engineering, and mathematics (STEM) subjects on students' learning: A preliminary meta-analysis. Journal of STEM Education: Innovations and Research, 12(5/6), 23-37.

Berry, E., \& Black, E. (1987). The integrative learning journal (or, getting beyond" true confessions" and" cold knowledge"). Women's Studies Quarterly, 15(3/4), 59-64.

Booth, A., McClean, M., \& Walker, M. (2009). Self, others and society: A case study of university integrative learning. Studies in Higher Education, 34(8), 929-939. doi:10.1080/03075070902773818

Brewe, E. A., Traxler, J., de la Garza, J., \& Kramer, L. H. (2013). Extending positive CLASS results across multiple instructors and multiple classes of modeling instruction. Physical Review. Physics Education Research, 9(2), 020116. Advance online publication. doi:10.1103/PhysRevSTPER.9.020116

Chamany, K., Allen, D., \& Tanner, K. (2008). Making biology learning relevant to students: Integrating people, history, and context into college biology teaching. CBE Life Sciences Education, 7(3), 267-278. Advance online publication. doi:10.1187/cbe.08-06-0029 PMID:18765745

Chandra, V., \& Watters, J. J. (2012). Re-thinking physics teaching with web-based learning. Computers \& Education, 58(1), 631-640. doi:10.1016/j.compedu.2011.09.010

Charleston, L. J., Adserias, R. P., Lang, N. M., \& Jackson, J. F. (2014). Intersectionality and STEM: The role of race and gender in the academic pursuits of African American women in STEM. Journal of Progressive Policy \& Practice, 2(3), 273-293.

Chemers, M. M., Zurbriggen, E. L., Syed, M., Goza, B. K., \& Bearman, S. (2011). The Role of efficacy and identity in science career commitment among underrepresented minority students. The Journal of Social Issues, 67(3), 469-491. Advance online publication. doi:10.1111/j.1540-4560.2011.01710.x

Cziprok, C. D., \& Miron, C. (2013, May). Creating an integrative learning environment using conceptual maps in physics lessons. In The International Scientific Conference eLearning and Software for Education. "Carol I" National Defense University. 
D’Souza, M. J., Curran, K. L., Olsen, P. E., Nwogbaga, A. P., \& Stotts, S. (2016). Integrative approach for a transformative freshman-level STEM curriculum. Journal of College Teaching and Learning, 13(2), 47-64. Advance online publication. doi:10.19030/tlc.v13i2.9632 PMID:27064213

Estrada, M., Burnett, M., Campbell, A. G., Campbell, P. B., Denetclaw, W. F., Gutiérrez, C. G., \& Zavala, M. (2016). Improving underrepresented minority student persistence in STEM. CBE Life Sciences Education, 15(3), es5. doi:10.1187/cbe.16-01-0038 PMID:27543633

Fazriyah, N., Supriyati, Y., \& Rahayu, W. (2017, February). The effect of integrated learning model and critical thinking skill of science learning outcomes. Journal of Physics: Conference Series, 812(1), 012014. doi:10.1088/1742-6596/812/1/012014

Flowers, L. A., Moore, J. L., Flowers, L. O., \& Clarke, M. J. (2011). The relationship between academic selfconcept and career self-efficacy among African-American males in STEM disciplines at two Historically Black Colleges and Universities: An exploratory study. Beyond Stock Stories and Folktales: African Americans' Paths to STEM Fields. Diversity in Higher Education, 11, 73-83. doi:10.1108/S1479-3644(2011)0000011008

Heredia, K., \& Lewis, J. E. (2012). A psychometric evaluation of the Colorado Learning Attitudes about Science Survey for use in chemistry. Journal of Chemical Education, 89(4), 436-441. doi:10.1021/ed100590t

Hewitt, K. M., Bouwma-Gearhart, J., Kitada, H., Mason, R., \& Kayes, L. J. (2019). Introductory biology in social context: The effects of an issues-based laboratory course on biology student motivation. CBE Life Sciences Education, 18(3), ar30. Advance online publication. doi:10.1187/cbe.18-07-0110 PMID:31298623

Holubova, R. (2008). Effective teaching methods: Project-based learning in physics. https://files.eric.ed.gov/ fulltext/ED504949.pdf

Humphreys, D. (2005). Why integrative learning? Why now? https://www.aacu.org/publications-research/ periodicals/why-integrative-learning-why-now

Jarrett-Thelwell, F. D., Burke, J. R., Poirier, J. N., \& Petrocco-Napuli, K. (2019). A comparison of student performance and satisfaction between a traditional and integrative approach to teaching an introductory radiology course on the extremities. The Journal of Chiropractic Education, 33(1), 21-29. doi:10.7899/JCE17-26 PMID:30444635

Karamustafaoglu, O. (2009). Active learning strategies in physics teaching. Energy Education Science and Technology, Part B. Social and Educational Studies, 1(1), 27-50.

Knight, J. K., \& Smith, M. K. (2010). Different but equal? How nonmajors and majors approach and learn genetics. CBE Life Sciences Education, 9(1), 34-44. doi:10.1187/cbe.09-07-0047 PMID:20194806

Labov, J., Reid, A., \& Yamamoto, K. (2010). Integrated biology and undergraduate science education: A new biology education for the twenty-first century? CBE Life Sciences Education, 9(1), 10-16. doi:10.1187/cbe.0912-0092 PMID:20194802

Lent, R. W., Brown, S. D., Sheu, H. B., Schmidt, J., Brenner, B. R., Gloster, C. S., \& Treistman, D. (2005). Social cognitive predictors of academic interests and goals in engineering: Utility for women and students at historically black universities. Journal of Counseling Psychology, 52(1), 84-92. doi:10.1037/0022-0167.52.1.84

Marušić, M., \& Sliško, J. (2012). Many high-school students don’t want to study physics: Active learning experiences can change this negative attitude! Revista Brasileira de Ensino de Física, 34(3), 1-11. Advance online publication. doi:10.1590/S1806-11172012000300013

McCarron, G. P., \& Inkelas, K. K. (2006). The gap between educational aspirations and attainment for firstgeneration college students and the role of parental involvement. Journal of College Student Development, 47(5), 534-549. Advance online publication. doi:10.1353/csd.2006.0059

McDermott, L. (1984). Research on conceptual understanding in mechanics. Physics Today, 37(7), 24-32. doi:10.1063/1.2916318

Museus, S. D. (2008). The model minority and the inferior minority myths: Understanding stereotypes and their implications for student learning. About Campus: Enriching the Student Learning Experience, 13(3), $2-8$. doi:10.1002/abc.252 
Museus, S. D., \& Quaye, S. J. (2009). Toward an intercultural perspective of racial and ethnic minority college student persistence. The Review of Higher Education, 33(1), 67-94. doi:10.1353/rhe.0.0107

National Science Foundation. (2015). Women, minorities and persons with disabilities in science and engineering (NSF 15-311). National Science Foundation.

Nehm, R. H. (2019). Biology education research: Building integrative frameworks for teaching and learning about living systems. Disciplinary and Interdisciplinary Science Education Research, 1(1), 15. https://diser. springeropen.com/articles/10.1186/s43031-019-0017-6

Park, M., \& Liu, X. (2016). Assessing understanding of the energy concept in different science disciplines. Journal of Science Education, 100(3), 483-516.

Perkins, K. K., Adams, W. K., Pollock, S. J., Finkelstein, N. D., \& Wieman, C. E. (2005, September). Correlating student beliefs with student learning using the Colorado Learning Attitudes about Science Survey. https://aip. scitation.org/doi/abs/10.1063/1.2084701

Reimer, L. C., Schenke, K., Nguyen, T., O'dowd, D. K., Domina, T., \& Warschauer, M. (2016). Evaluating promising practices in undergraduate STEM lecture courses. Journal of the Social Sciences, 2(1), 212-233. doi:10.1353/rus.2016.0003

Rhodes, T. (2010). Assessing outcomes and improving achievement: Tips and tools for using rubrics. Association of American Colleges and Universities.

Sasso, A. (2008). African Americans studying STEM: Parsing the numbers. Science Magazine. http:// sciencecareers.sciencemag.org/career_magaziiie/previous_issues/articles/2008_05_1

Sawtelle, V., Brewe, E., \& Kramer, L. (2009). Validation study of the Colorado Learning Attitudes about Science Survey at a Hispanic-serving institution. Physical Review. Physics Education Research, 5(2), 023101. Advance online publication. doi:10.1103/PhysRevSTPER.5.023101

Semsar, K., Knight, J. K., Birol, G., \& Smith, M. K. (2011). The Colorado Learning Attitudes about Science Survey (CLASS) for use in biology. CBE Life Sciences Education, 10(3), 268-278. Advance online publication. doi:10.1187/cbe.10-10-0133 PMID:21885823

Shaw, E. J., \& Barbuti, S. (2010). Patterns of persistence in intended college major with a focus on STEM majors. NACADA Journal, 30(2), 19-34. doi:10.12930/0271-9517-30.2.19

Sweeney, C., O'Sullivan, E., \& McCarthy, M. (2015). Keeping it real: Exploring an interdisciplinary breaking bad news role-play as an integrative learning opportunity. The Journal of Scholarship of Teaching and Learning, 15(2), 14-32. doi:10.14434/josotl.v15i2.13262

Taber, K. S. (2000). Should physics teaching be a research-based activity? Physics Education, 35(3), 163-168. doi:10.1088/0031-9120/35/3/303

Tsui, L. (2007). Effective strategies to increase diversity in STEM fields: A review of the research literature. The Journal of Negro Education, 76(4), 555-581.

van Kesteren, M., Brown, T., \& Wagner, A. (2016). Interactions between memory and new learning: Insights from fMRI multivoxel pattern analysis. Frontiers in Systems Neuroscience, 10(46), 1-5. doi:10.3389/fnsys.2016.00046 PMID:27303274

Walshe, N., O'Brien, S., Murphy, S., \& Hartigan, I. (2013). Integrative learning through simulation and problembased learning. Clinical Simulation in Nursing, 9(2), e47-e54. doi:10.1016/j.ecns.2011.08.006

Zaykin, D. V. (2011). Optimally weighted Z-test is a powerful method for combining probabilities in meta-analysis. Journal of Evolutionary Biology, 24(8), 1836-1841. doi:10.1111/j.1420-9101.2011.02297.x PMID:21605215

Zeldin, A. L., Britner, S. L., \& Pajares, F. (2008). A comparative study of the self-efficacy beliefs of successful men and women in mathematics, science, and technology careers. Journal of Research in Science Teaching, 45(9), 1036-1058. doi:10.1002/tea.20195 
Tennille D. Presley, Ph.D., is an Associate Professor of Physics at Winston-Salem State University. She obtained her B.S. degree in Interdisciplinary Physics from North Carolina A \& T State University and her M.S. and Ph.D. degrees in Biophysics from The Ohio State University. Dr. Presley completed postdoctoral studies at Wake Forest University in both the Translational Science Center and the Department of Physics. Her research focuses on studying the effects of nitric oxide and its derivatives, which led to a number of international and national presentations and publications to include the book "Biophysics of the Senses." Dr. Presley prides herself on striving for excellence in research, teaching, and service.

Noelle Harp is a young professional from Greensboro, NC who received her B.S. in Computer Science from Winston-Salem State University in May 2017. Ms. Harp currently works as a software engineer for Booz Allen Hamilton and is knowledgeable in the following languages: Java, Python, HTML, Javascript, and SQL.

Latrise Holt received her BS in Biology in May 2019 and works as a pharmacy technician and a technologist in a chemistry department. She has performed research in the area of the Scholarship of Teaching and Learning.

Destini Samuel is a Biology degree recipient with aspirations of becoming a physician's assistant.

Jill Harp, Ph.D., is Professor of Biochemistry at Winston-Salem State University (WSSU), Adjunct Professor at Wake Forest University Health Sciences (WFUHS), former chair of the Biological Sciences Department and currently directing WSSU's Biomedical Research Infrastructure Center. She received her BS degree from the York College-City University of New York and her Ph.D. from the University of Maryland-College Park. Dr. Harp is a bioorganic chemist with training in pharmacology and conducts research related to CNS disease and disorders. In 2011, Dr. Harp received the Board of Governors award for Excellence in Teaching, the highest award given by the state. Dr. Harp is also involved in the assessment of student learning, serves(d) on various WSSU's Leadership Teams, Assessment Committees, and professional development initiatives. Faculty development is important to Dr. Harp as she has assisted through her service on committees, the Internal Review Board, Research Initiation Program Committee, and facilitating faculty workshops. These collaborative activities have also led to several conference presentations to include, but not limited to, writing, critical thinking, curriculum enhancements, and faculty development. Dr. Harp is also involved with outreach activities involving underrepresented K12 youth. She is one of the founders of SciTech which incorporates performing hands-on experiments with elementary through high school-aged students. 